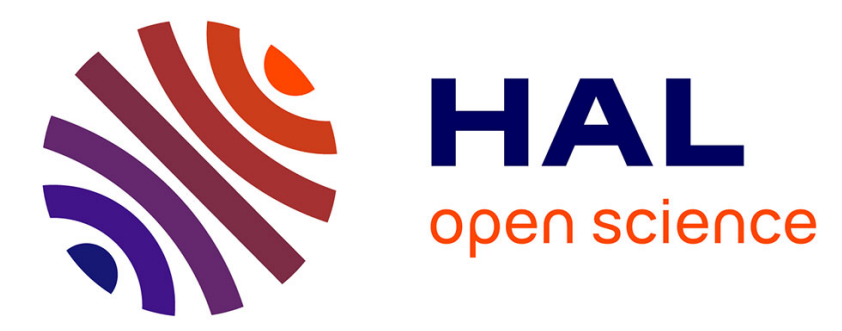

\title{
Reduced aggrecan expression affects cardiac outflow tract development in zebrafish and is associated with bicuspid aortic valve disease in humans
}

Pierre Rambeau, Emilie Faure, Alexis Theron, Jean-François Avierinos, Chris Jopling, Stéphane Zaffran, Adèle Faucherre

\section{To cite this version:}

Pierre Rambeau, Emilie Faure, Alexis Theron, Jean-François Avierinos, Chris Jopling, et al.. Reduced aggrecan expression affects cardiac outflow tract development in zebrafish and is associated with bicuspid aortic valve disease in humans. International Journal of Cardiology, 2017, 249, pp.340 - 343. 10.1016/j.ijcard.2017.09.174 . inserm-01617193

\section{HAL Id: inserm-01617193 https://www.hal.inserm.fr/inserm-01617193}

Submitted on 29 Mar 2018

HAL is a multi-disciplinary open access archive for the deposit and dissemination of scientific research documents, whether they are published or not. The documents may come from teaching and research institutions in France or abroad, or from public or private research centers.
L'archive ouverte pluridisciplinaire HAL, est destinée au dépôt et à la diffusion de documents scientifiques de niveau recherche, publiés ou non, émanant des établissements d'enseignement et de recherche français ou étrangers, des laboratoires publics ou privés. 


\title{
Reduced aggrecan expression affects cardiac outflow tract development in zebrafish and is associated with bicuspid aortic valve disease in humans
}

\author{
Pierre Rambeau $^{\mathrm{a}}$, Emilie Faure ${ }^{\mathrm{b}}$, Alexis Théron ${ }^{\mathrm{b}, \mathrm{c}}$, Jean-François Avierinos ${ }^{\mathrm{b}, \mathrm{d}}$, Chris Jopling ${ }^{\mathrm{a}}$, \\ Stéphane Zaffran ${ }^{\mathrm{b}}$, Adèle Faucherre ${ }^{\mathrm{a}, *}$ \\ a IGF, LabexICST, CNRS, INSERM, Univ Montpellier, Montpellier, France \\ b Aix Marseille Univ, INSERM, GMGF, Marseille, France \\ c Service de Chirurgie Cardiaque, AP-HM, Hôpital de la Timone, 13005 Marseille, France \\ d Service de Cardiologie, AP-HM, Hôpital de la Timone, 13005 Marseille, France
}

Received 19 June 2017

Received in revised form 21 August 2017

Accepted 18 September 2017

Available online 24 September 2017

\section{Keywords:}

Aggrecan

Hemodynamic

Bicuspid aortic valve

\begin{abstract}
A B S T R A C T
Hemodynamic forces have been known for a long time to regulate cardiogenic processes such as cardiac valve development. During embryonic development in vertebrates, the outflow tract (OFT) adjacent to the ventricle comes under increasing hemodynamic load as cardiogenesis proceeds. Consequently, extracellular matrix components are produced in this region as the cardiac cushions form which will eventually give rise to the aortic valves. The proteoglycan AGGRECAN is a key component of the aortic valves and is frequently found to be deregulated in a variety of aortic valve diseases. Here we demonstrate that aggrecan expression in the OFT of developing zebrafish embryos is hemodynamically dependent, a process presumably mediated by mechanosensitive channels. Furthermore, knockdown or knockout of aggrecan leads to failure of the OFT to develop resulting in stenosis. Based on these findings we analysed the expression of AGGRECAN in human bicuspid aortic valves (BAV). We found that in type $0 \mathrm{BAV}$ there was a significant reduction in the expression of AGGRECAN. Our data indicate that aggrecan is required for OFT development and when its expression is reduced this is associated with BAV in humans.
\end{abstract}

\section{Introduction}

Arterial valve leaflets are composed of three distinct layers of ExtraCellular Matrix (ECM) called fibrosa, spongiosa and ventricularis. The spongiosa layer is particularly rich in proteoglycans which will provide compressive properties to the tissue and allow the leaflet to change shape during the cardiac cycle. Indeed, valves are submitted to extreme hemodynamic forces such as shear stress and cyclic strain that will subsequently regulate both their development and function. Studies in chick and zebrafish have shown that disruption of the hemodynamic forces results in cardiac valves defects including defects of the outflow tract (OFT) cushion formation and severe heart defects associated with a total absence of valves [1,2]. Among valve diseases, bicuspid aortic valve (BAV) is one of the most common pathologies found in patients, occurring in $1-2 \%$ of living births and are frequently associated with aortic stenosis, regurgitation, endocarditis and calcified valves [3].

AGGRECAN is one of the major members of the large proteoglycans found in cartilage and provides the ability to resist compressive loads

\footnotetext{
* Corresponding author at: Institut de Génomique Fonctionnelle, 141 rue de la Cardonille, 34094 Montpellier cedex 05, France.

E-mail address: adele.faucherre@igf.cnrs.fr (A. Faucherre).
}

[4]. A recent transcriptomic study of human BAV has shown that AGGRECAN expression is decreased in BAV patients with mild calcification compared with calcified tricuspid aortic valve (TAV) [5]. Zebrafish possess 2 aggrecan paralogues, aggrecanA (acana) and aggrecanB (acanb). Here we show that acana expression in the zebrafish OFT is dependent on hemodynamic forces and that knockdown or knockout of acana during development induces cardiovascular defects. Moreover, we observe that in humans, AGGRECAN (ACAN) expression is reduced in type 0 BAV compared to normal TAV.

\section{Materials and methods \\ 2.1. Zebrafish strains and husbandry}

Zebrafish were maintained under standardized conditions [6] and experiments were conducted in accordance with the European Communities council directive 2010/63. The $\operatorname{Tg}($ fli1a:GFP)y1 line was provided by the CMR $[B]$.

\subsection{Ruthenium Red treatment}

At 3dpf, larvae were incubated in a 10 or $20 \mu \mathrm{M}$ Ruthenium Red (RR) solution (Sigma, R2751) in E3 medium during $24 \mathrm{~h}$. 
ISH were performed as described previously $[7,8]$ (see Supplementary information). For RR treated fish, the proteinase $\mathrm{K}$ treatment was reduced to $15 \mathrm{~min}$.

\subsection{Morpholinos and injections}

Morpholino oligonucleotides were obtained from Gene Tools (Philomath, OR, USA) and injected into one-cell stage embryos (see Supplementary information).

\subsection{CRISPR/Cas9}

Acana target sequences were identified using ZiFiT online software [9]. $150 \mathrm{pg}$ of acana gRNA was co-injected with nls-Cas9 protein (N.E.B) (see Supplementary information).

\subsection{Cardiovascular parameters analysis}

Cardiovascular parameters were determined using the MicroZebraLab ${ }^{\mathrm{TM}}$ software from ViewPoint [10] (see Supplementary information).

\subsection{Real-time quantitative Reverse Transcription Polymerase Chain Reaction ( $q R T-P C R$ )}

Human aortic valve tissues were collected after surgery by the Department of cardiac surgery at "La Timone" Hospital, Marseille, France. The protocol was evaluated and authorised by the "CPP Sud Méditerranée" $n^{\circ}$ : 13.061. and by the "Agence de la biomedicine" $n^{\circ} \mathrm{PFS} 14-011$. (see Supplementary information).

\section{Results}

3.1. AggrecanA is expressed in the zebrafish OFT and is dependent on hemodynamic forces

To determine the expression pattern of aggrecan, we performed in situ hybridization (ISH) on 4 days post-fertilization (dpf) embryos using antisense acana and acanb probes. Acana showed a high expression in craniofacial cartilage as previously described [11], however we were also able to observe a clear expression of acana in the OFT (Fig. 1.A). In contrast, we could not detect any acanb expression in this cardiac structure (Fig. 1.B). In order to confirm that acana expression was localised to the OFT, we performed double fluorescent ISH on 4dpf larvae using antisense probes targeting acana and elastin $b$ (elnb), an abundant component of the zebrafish OFT [12]. In this manner we were able to observe that acana expression co-localised with elnb expression in the OFT (Fig. 1.C$\mathrm{H})$. Because ECM composition can be modulated by hemodynamic forces, we sought to determine whether this was the case for acana expression in the OFT. To achieve this, we used a previously described morpholino targeting tnnt 2 which effectively stops the heart from beating [13]. In this manner we found that tnnt2 morphants display an apparent lack of acana expression in the OFT (Fig. 1.I). Previous research has indicated that mechanosensitive ion channels (MSC) can detect hemodynamic forces and trigger valve formation [14]. To determine whether MSC could mediate acana expression in response to hemodynamic forces, we employed the nonselective MSC blocker Ruthenium Red (RR). In
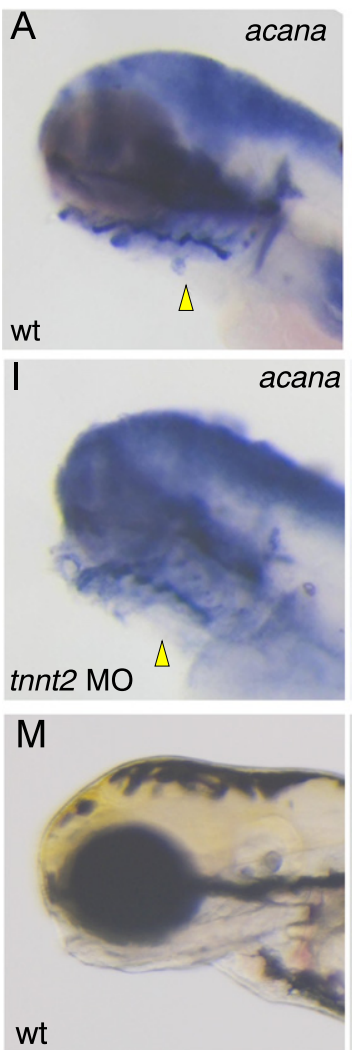

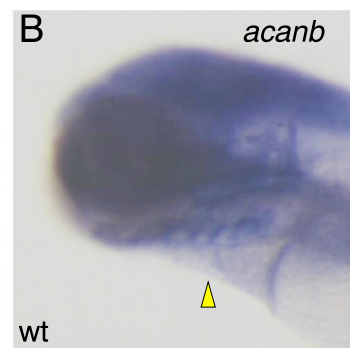

J
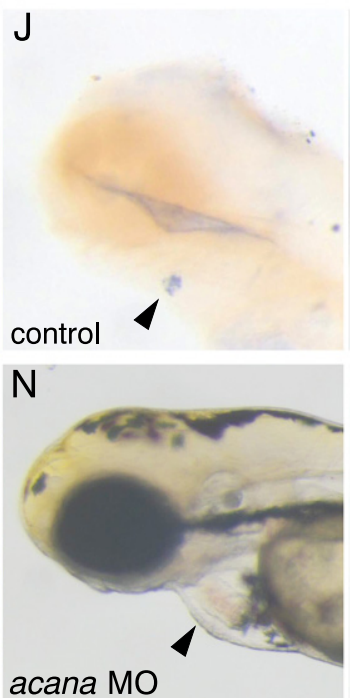
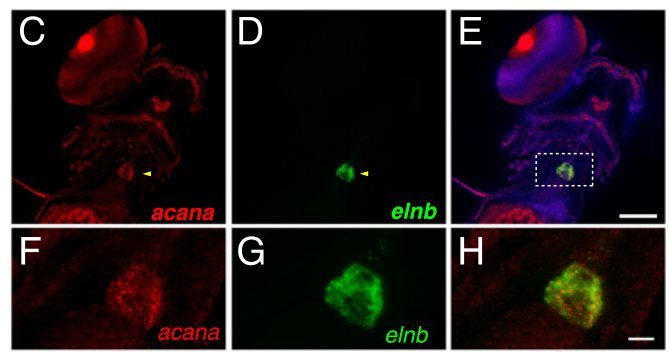

$\mathrm{K}$

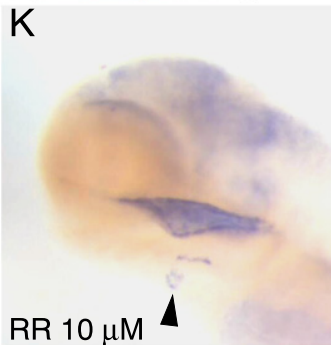

$\mathrm{L}$

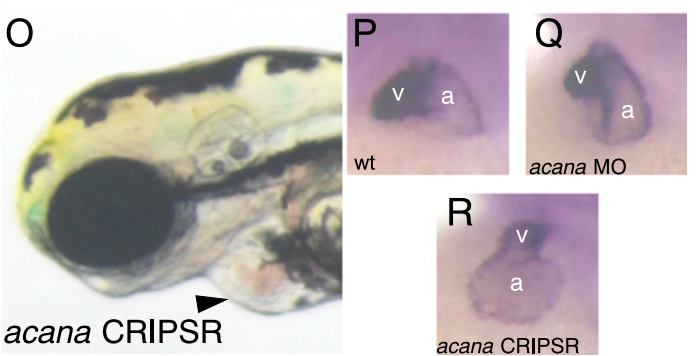

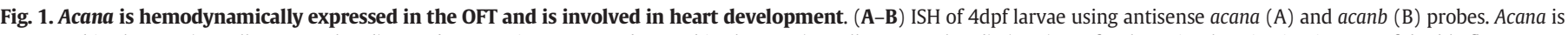

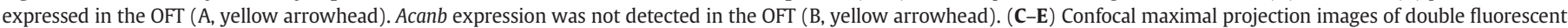

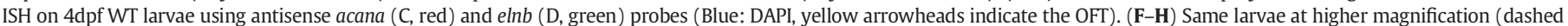

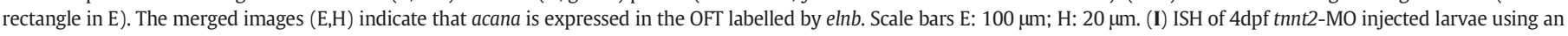

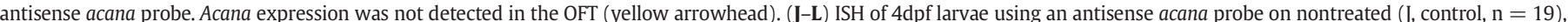

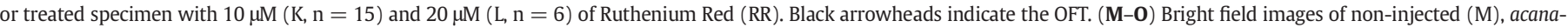

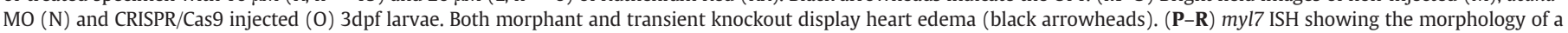
wild-type heart (P) or of hearts from acana-MO (Q) and CRISPR/Cas9 injected (R) 3dpf larvae. Both morphant and transient knockout display a larger atrium (v: ventricle; a: atrium). 
this manner we could observe that larvae incubated with RR showed a dose responsive decrease of acana expression in the OFT (Fig. 1.J-L).

\subsection{AggrecanA is involved in cardiac development}

Due to its expression in the OFT, we speculated that acana may play a role in cardiac development. To answer this question we adopted a morpholino (MO) mediated approach targeting an internal splice site. Injection of this MO produced a phenotype characterized by defective cardiogenesis including a larger atrium and associated edema at $3 \mathrm{dpf}$ (Fig. 1.M-N, P-Q). To confirm the specificity of the phenotype, we performed several control experiments (Suppl. Fig. 1 and Suppl. information). We also implemented a previously described transient CRISPR/ Cas9 knockout strategy $[15,16]$. In this manner we were able to observe zebrafish embryos displaying a similar cardiac phenotype to that observed when acana was knocked-down with a MO (Fig. 1.O,R). Although this approach will result in a mosaic knockout of acana, all embryos which displayed a cardiac phenotype tested positive for $\mathrm{KO}$ of acana by T7 assay ( $n=6 / 44$ ) (Suppl. Fig. 2). Together these results indicate that loss of acana either by knockdown or knockout leads to perturbed cardiogenesis.

To better understand how the OFT has been affected, we analysed this structure in $\operatorname{Tg}(f l i 1 a: G F P) y 1$ larvae which express GFP in all endothelial cells. At 3dpf, the wild-type OFT displays a typical "pear-shape" structure (Fig. 2.A). By contrast, in the acana morphants this structure has failed to develop (Fig. 2.B). In parallel, we also analysed a number of cardiovascular parameters such as heart rate and stroke volume. No significant differences were observed in the heart rate between the wild-type and acana morphants (Suppl. Fig. 3). However, the cardiac
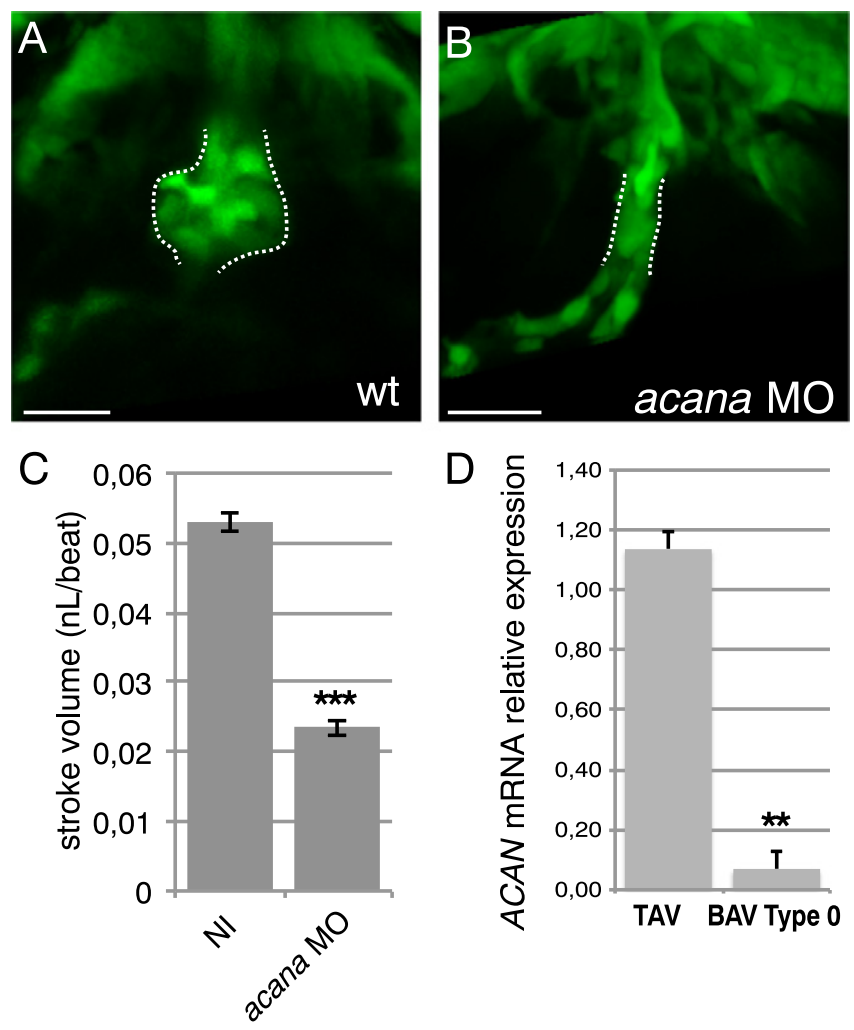

Fig. 2. Knockdown of acana disrupts OFT development and AGGRECAN expression is modified in human BAV patients. (A,B) Confocal maximal projection image of 3dpf $\operatorname{Tg}$ (fli1a:GFP)y1 OFT from WT (A) and acana morphant (B) larvae. White dashed lines indicate the OFT. (C) Graph showing the difference in stroke volume between noninjected $(\mathrm{NI}, \mathrm{n}=13)$ and acana morphants $(\mathrm{n}=12){ }^{* * *} \mathrm{p}<0.001$ (Student's $t$-test) (D) Graph showing relative mRNA expression of ACAN between TAV controls $(n=4)$ and BAV Type $0(\mathrm{n}=2){ }^{* *} \mathrm{p}<0.05$ (nonparametric Mann and Withney test). Error bars represent mean \pm SEM in all histograms. output and stroke volume were significantly decreased in acana morphants when compared to controls (Fig. 2.C and Suppl. Fig. 3). We also recorded high-speed movies of the beating embryonic heart and observed that in acana morphants there was a significant amount of blood regurgitation between the ventricle and the atrium, most likely caused by failed OFT development, forcing blood back through the AV canal (Suppl. movies M1 and M2).

\subsection{ACAN expression is reduced in human BAV patients}

Based on our findings in zebrafish, we hypothesised that reduced AGGRECAN (ACAN) expression may also be associated with aortic valve diseases such as BAV. Firstly, we determined the relative abundance of $A C A N$ in the aortic valve by qPCR and were able to detect $A C A N$ expression during foetal valve development in human (Suppl. Fig. 4). By 13 weeks of gestation, the ACAN expression greatly increased and this expression was even more abundant in adult valves. To assess the possibility that ACAN expression could be reduced in BAV patients, we performed RT-qPCR analysis using RNA extracted from aortic valves surgically removed from patients diagnosed type 0 "pure" BAV. As a control we used RNA extracted from normal TAV. We observed a significant ( 16 fold) decrease in the expression of ACAN in the type 0 BAV samples when compared to the control TAV samples (Fig. 2.D).

\section{Discussion}

Here we have shown that hemodynamically dependent acana expression is required for OFT development in zebrafish. Moreover, we showed that a MSC could be the sensor of these hemodynamic forces. It has recently been shown that the Trpv4 MSC, a target of RR, is involved in atrioventricular valve development in response to hemodynamic forces [14]. However, because RR is non-specific, we cannot determine the true identity of the MSC at this juncture. Because the analogous region in humans will give rise to the aortic valves, we also analysed ACAN expression during human aortic valve development and in patients who suffer from type $0 \mathrm{BAV}$ we found a significant reduction when compared to TAV.

Because of the rarity of this condition, we were only able to analyse relatively few patients, however the difference was in excess of 16 fold. It will therefore be necessary to expand this cohort to determine fully the reduction in the expression of AGGRECAN associated with BAV type 0 . At present little is known about the genetic causes of BAV, with only a handful of genes thus far identified and, as one can imagine, there is even less known about what causes the different types of BAV. Although we cannot categorically state that reduced AGGRECAN expression is the root cause of type $0 \mathrm{BAV}$, its association with this condition does appear to be significant. Decreased AGGRECAN expression with BAV type 0 may not be so surprising considering it is required to strengthen and provide rigidity to the developing valves, and when this is lost the developmental process will malfunction. Why AGGRECAN expression is reduced in BAV type 0 remains unclear at this juncture, however it is possible that defective hemodynamics or defective mechanosensation of these forces during OFT development could be involved with this condition.

Supplementary data to this article can be found online at https://doi. org/10.1016/j.ijcard.2017.09.174.

\section{Conflict of interest}

The authors report no relationships that could be construed as a conflict of interest.

\section{Acknowledgements}

A.F is currently supported by a Labex ISCT postdoctoral fellowship with previous support provided by a Fondation Lefoulon-Delalande 
postdoctoral fellowship. P.R is supported by the Labex ISCT PhD program. C.J is supported by an INSERM ATIP-AVENIR grant and a Marie Curie CIG (PCIG12-GA-2012-332772). A.F, P.R and C.J are members of the Laboratory of Excellence "Ion Channel Science and Therapeutics» supported by a grant from the ANR. Work in C.J lab is supported by a grant from the Fondation Leducq and by the Fédération pour la Recherche sur le Cerveau (FRC). Work in S.Z lab is supported by INSERM, the Fédération Française de Cardiologie, and the Association Française contre les Myopathies (AFM-Telethon).

\section{References}

[1] V. Menon, J.F. Eberth, R.L. Goodwin, J.D. Potts, Altered hemodynamics in the embryonic heart affects outflow valve development, J. Cardiovasc. Dev. Dis. 2 (2015) 108-124.

[2] J.R. Hove, R.W. Koster, A.S. Forouhar, G. Acevedo-Bolton, S.E. Fraser, M. Gharib, Intracardiac fluid forces are an essential epigenetic factor for embryonic cardiogenesis, Nature 421 (2003) 172-177.

[3] R. Padang, R.D. Bagnall, C. Semsarian, Genetic basis of familial valvular heart disease, Circ. Cardiovasc. Genet. 5 (2012) 569-580.

[4] J. Lincoln, A.W. Lange, K.E. Yutzey, Hearts and bones: shared regulatory mechanisms in heart valve, cartilage, tendon, and bone development, Dev. Biol. 294 (2006) 292-302.

[5] R. Padang R.D. Bagnall, T. Tsoutsman, P.G. Bannon, C. Semsarian, Comparative transcriptome profiling in human bicuspid aortic valve disease using RNA sequencing, Physiol. Genomics 47 (2015) 75-87.
[6] M. Westerfield, The zebrafish book, A Guide for the Laboratory Use of Zebrafish (Danio rerio), 4th ed.Univ. of Oregon Press, Eugene, 2000.

[7] T. Brend, S.A. Holley, Zebrafish whole mount high-resolution double fluorescent in situ hybridization, J. Vis. Exp. (2009).

[8] C. Thisse, B. Thisse, High-resolution in situ hybridization to whole-mount zebrafish embryos, Nat. Protoc. 3 (2008) 59-69.

[9] J.D. Sander, P. Zaback, J.K. Joung, D.F. Voytas, D. Dobbs, Zinc Finger Targeter (ZiFiT): an engineered zinc finger/target site design tool, Nucleic Acids Res. 35 (2007) W599-605.

[10] T. Parker, P.A. Libourel, M.J. Hetheridge, R.I. Cumming, T.P. Sutcliffe, A.C. Goonesinghe, et al., A multi-endpoint in vivo larval zebrafish (Danio rerio) model for the assessment of integrated cardiovascular function, J. Pharmacol. Toxicol. Methods 69 (2014) 30-38.

[11] J.S. Kang, Y. Kawakami, Y. Bekku, Y. Ninomiya, J.C. Izpisua Belmonte, T. Oohashi, Molecular cloning and developmental expression of a hyaluronan and proteoglycan link protein gene, crtl1/hapln1, in zebrafish, Zool. Sci. 25 (2008) 912-918.

[12] M. Miao, A.E. Bruce, T. Bhanji, E.C. Davis, F.W. Keeley, Differential expression of two tropoelastin genes in zebrafish, Matrix Biol. 26 (2007) 115-124.

[13] A.J. Sehnert, A. Huq, B.M. Weinstein, C. Walker, M. Fishman, D.Y. Stainier, Cardiac troponin $\mathrm{T}$ is essential in sarcomere assembly and cardiac contractility, Nat. Genet. 31 (2002) 106-110.

[14] E. Heckel, F. Boselli, S. Roth, A. Krudewig, H.G. Belting, G. Charvin, et al., Oscillatory flow modulates mechanosensitive klf2a expression through trpv4 and trpp2 during heart valve development, Curr. Biol. 25 (2015) 1354-1361.

[15] B. Willems, S. Tao, T. Yu, A. Huysseune, P.E. Witten, C. Winkler, The Wnt Co-receptor Lrp5 is required for cranial neural crest cell migration in zebrafish, PLoS One 10 (2015), e0131768.

[16] Y. Moriyama, F. Ito, H. Takeda, T. Yano, M. Okabe, S. Kuraku, et al., Evolution of the fish heart by sub/neofunctionalization of an elastin gene, Nat. Commun. 7 (2016) 10397. 